Original Research Paper

\title{
About the Internal Structure of a Bone and its Functional Role
}

\author{
${ }^{1}$ Antonio Apicella, ${ }^{1}$ Raffaella Aversa, ${ }^{1}$ Francesco Tamburrino and ${ }^{2}$ Florian Ion Tiberiu Petrescu \\ ${ }^{I}$ Advanced Material Lab, Department of Architecture and Industrial Design, \\ Second University of Naples, 81031 Aversa (CE), Italy \\ ${ }^{2}$ ARoTMM-IFToMM, Bucharest Polytechnic University, Bucharest, (CE), Romania
}

Article history

Received: 16-05-2018

Revised: $18-05-2018$

Accepted: 24-05-2018

Corresponding Author:

Florian Ion Tiberiu Petrescu

ARoTMM-IFToMM,

Bucharest Polytechnic

University, Bucharest,

(CE), Romania

Email: scipub02@gmail.com
Abstract: The human skeleton has the primary role of supporting all the organs that make up the body and at the same time to protect them permanently. It is made up so that it can hold and hold together all internal human organs, protecting them permanently, but also allowing them to move and exercise all their functionalities. This paper wants to show the structure of a healthy, young bone, its functionalities, its role in a human being and some aspects of how bone health can prolong our lives, while a diseased bone organism will it gets sick and ends up losing his vital energy, mobilizing and in a final will dying. A bone is first produced from a cartilage. The cartilage then slowly transforms into a bone through a complex process. When a baby floats in his mother's womb, the developing organism begins to build its shape and causes the cartilage to do so. Cartilage is a tissue that is not as rough as bones but much more flexible and, in a way, more functional. A large amount of fetal cartilage starts to turn into bone, the process itself is called ossification. When ossification takes place, cartilage (which does not contain salts or minerals in it) begins to calcify; that is, the layers of calcium and phosphate salts begin to accumulate on the cells of the cartilage slowly. These cells, surrounded by more and more minerals, aging and dying. This leaves some small pockets of separation in the modified cartilage and small blood vessels grow in these cavities. Now, some specialized cells called osteoblasts start traveling in the developing bone through these blood vessels. These cells produce a substance consisting of collagen fibers and also help in the collection of calcium that is deposited along this fibrous substance (A common analogy for this design is reinforced concrete, which is a network of metal bars coated with concrete mixture). After a while, osteoblasts become part of the mixture, turning into inferior osteocytes, a retracted version of osteoblasts that continue to sneak but do not distance themselves too much from the blood vessels. This newly formed osteocyte network helps to form the sponge-like network of spongy bone. The oscillating bone is not soft, but looks spongy, meaning that it remains in its construction. These spaces help first of all to transfer the external pressure stress to the entire bone (distribution of external pressure on the entire surface of the bone) and secondly, these spaces also contain the marrow. Channel canals, called canaliculi, run on all calcified bone parts, allowing nutrients, gases, toxins and waste to pass through them. The more interesting part is that if the number of bones originally formed is much higher, in the newborn, immediately the bones begin to jug with each other, greatly reducing their total number, thus lowering the mobility and agility of the infant, in order to achieve a stature instead bigger, stronger, stronger, but that will not be as mobile as that of the newborn baby.

Keywords: Biomechanics, Biomaterials, Bone, Cartilage, Ossification, Osteoblasts, Osteocytes, Bones Structure 


\section{Introduction}

The human skeleton has the primary role of supporting all the organs that make up the body and at the same time to protect them permanently.

It is made up so that it can hold and hold together all internal human organs, protecting them permanently, but also allowing them to move and exercise all their functionalities.

It is important that the protection is permanently active and at the same time the human skeleton maintains itself and wholeheartedly healthy. It should first be noted that the bone skeleton does not appear to be done, but it builds slowly, grows, starting with the fetus in its mother's womb. The more interesting part is that if the number of bones originally formed is much higher, in the newborn, immediately the bones begin to jug with each other, greatly reducing their total number, thus lowering the mobility and agility of the infant, in order to achieve a stature instead bigger, stronger, stronger, but that will not be as mobile as that of the newborn baby.

Human movement or motility is a feature of the human being innate, but an improved lifetime, to carry through muscle skeletal movements of body segments thereof or entirely, in response to external or internal stimuli, in order to harmonize its relations natural or social environment there.

On the basis of motility are a number of factors neuroendocrine - muscle and metabolites which make the movement in space of the human body or its segments.

Elements which defining human motility are: The act, the action and motor activity.
The human skeletal muscle system plays a major role in the movement which is a feature of the living world. Movement is based on the contractility, which is the ability of a specialized tissue, muscle tissue to respond to the action of pathogenic agents by functional changes under the leadership of the nervous system.

The essential difference to the animal world consists of two major evolutionary lines: Development, on the one hand, the cerebral cortex and its functions and achieve a bipedal vertical position of the body, on the other hand.

The activity of human motion is an unconditioned reflex activity that is based on the conditioned reflex activity (Fig. 1).

Leonardo Da Vinci was not just one of the great artists of the Renaissance he also was the first pioneer in the understanding of human anatomy. Da Vinci's most penetrating anatomical studies began in 1506 with his dissection of a 100-year-old man, whose peaceful death he had just witnessed. His earlier dissections and drawings were of animals - oxen, horses, a bear and birds - and many of his first human images were anatomically inaccurate representations of received wisdom about the structures, functions and connections of the human body. He acquired his first human skull in 1489 and the works displayed in this impeccably curated and beautifully presented exhibition take us up to 1513 , during which time he dissected around 30 corpses. His anatomist friend and guide, Professor Marcantonio Della Torre, died of the plague in 1511 and 2 years later da Vinci dropped his great anatomical project. His wonderful drawings and notes went unpublished and undiscovered for centuries.

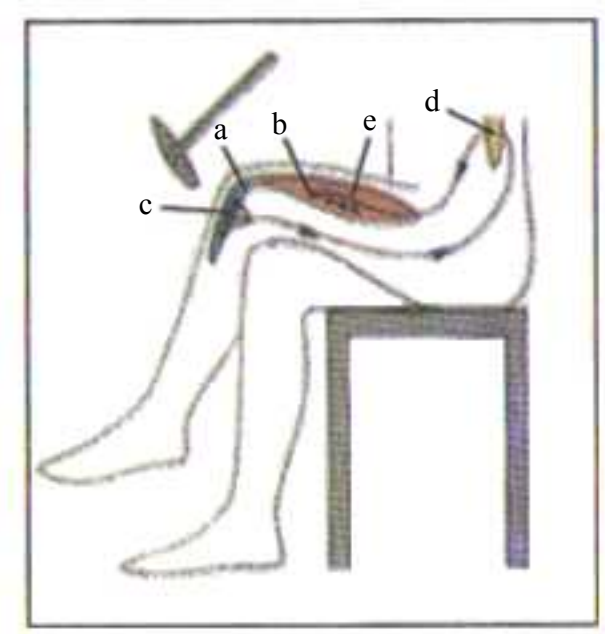

Unconditioned reflex act; known patellar reflex: a-tendon, b-muscle, c-sensitive nerve endings, d-spinal nerve center, e-motor nerve

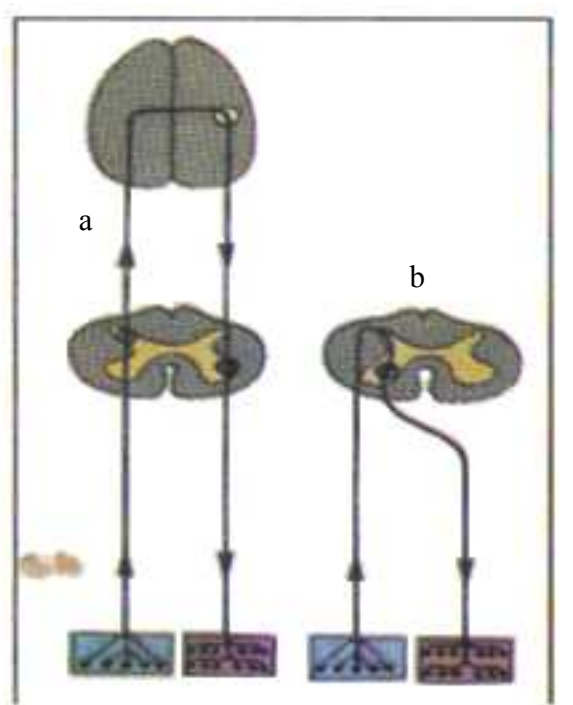

A-conditioned reflex arc with cortical center, b-unconditioned reflex arc medullary

Fig. 1: Conditioned and unconditioned reflex arc (act) 
He wanted to be 'true to nature' in his painting, so he researched the appearance of the physical world in all its aspects, especially the human body.

As an artist, sculptor and engineer, da Vinci wanted to know not only how the body was constructed and how it worked, but also where the emotions came from and how they were expressed. His meticulous dissections and drawings of muscles, nerves and vessels reflected the engineer in him, but he struggled to move on from ancient notions of bodily functions, although his painstaking empirical work got him there in the end. He discovered that the humours did not reside in three cerebral ventricles, that the heart, not the liver, was at the core of the blood system and was the first to describe atherosclerosis and hepatic cirrhosis. He used molten wax to define the anatomical cerebral ventricles and made a model glass aorta to study the flow of blood across the aortic valve, using water containing grass seeds to observe patterns of flow. He described the coronary sinuses almost 200 years before Valsalva gave them his name and, 120 years before Harvey, was surely only a heartbeat away from grasping the idea of the circulation of the blood.

As well as being a matchless draughtsman, da Vinci must have been an extremely skilled dissector; his postmortem material was not chilled, embalmed, or fixed and fine dissection of the brain and other soft tissues must have been a huge challenge. There are few, if any, drawings of the internal appearances of organs such as the kidneys, liver, spleen and gut, perhaps for that reason.

His extensive annotations, in his unique 'mirror writing' (he was left-handed and all his script was laterally inverted), combined with the lovely ink drawings, make each page of his priceless folio a thing of great beauty. Why he never published this material is a mystery. I had understood that dissection, even of executed criminals, was frowned upon and that he had to hide his notebooks, but the senior curator of the exhibition, Martin Clayton, is clear that dissection was not opposed by the Church. When da Vinci returned to Rome he was accused of 'unseemly conduct' (and perhaps witchcraft) and ceased his anatomical studies. The world had to wait for a generation before Vesalius published his definitive account of human anatomy in "De humani corporis fabrica" in 1543 (Roger, 2015).

The normal position of the human being is orthostatism - straight body posture achieved by bipedal position $(\mathrm{bi}=$ two $=$ pods feet). Standing primarily involves greater rigidity of the spine and the broad support and firm legs which became plantigrade (sole applied to the soil). The abutment surface of the feet is the polygon supporting the body. The centre of gravity of the human is located in the abdomen, in the anterior part of the lumbar region of the spine. To ensure vertical position, its projection should be placed in the middle of the polygon of support.
This is achieved by a coordinated contraction of the two antagonistic muscle groups (anterior and posterior) of the skeletal muscle that counteracts by their action against the force of gravity, making the body balance.

Locomotor adaptations (muscular skeletal system) to standing and human bipedal locomotion are numerous. Different body bone segment is extended or obtuse angles very open with each other.

The legs present important adaptations like widening the pelvic (basin) for supporting the abdominal organs, buttocks muscles strong development (of a seat) and the femur (the long bone of the body), providing a right angle between the bones of the lower leg and foot, palate formation (sole curvature), (Elena, 1976; New Atlas of Human Anatomy, 2000; Pittaccio et al., 2015; Viscuso and Pittaccio, 2012; Priadko et al., 2017; Nikolaev et al., 2008; Yang et al., 2013; Yang and Wayman, 1992; Van Humbeeck, 2010; Otsuka and Ren, 1999; Otsuka et al., 1971; Velázquez and Pissaloux, 2012; Melton and Mercier, 1980; Knowles and Smith, 1981; Miyazaki et al., 1984; Lahoz and Puértolas, 2004; Matsumoto et al., 1987; Šittner et al., 2014; Duerig, 1990; Naresh et al., 2016; Ziólkowski, 2012; Shaw et al., 2008; Aversa et al., 2018; $2017 \mathrm{a} ; 2017 \mathrm{~b}$; 2017c; 2016a; 2016b; 2016c; 2016d; 2016e; 2016f; 2016g; 2016h; 2016i; Mirsayar et al., 2017; Petrescu et al., 2015; 2016a; 2016b; 2016c; Petrescu and Calautit, 2016a; 2016b; Kus and Breczko, 2010; Otsuka et al., 1976; Yang and Wayman, 1992; Harrison and Hodgson, 1972; Hanlon et al., 1967; Huang et al., 2003; Sofla et al., 2008; Tamburrino, 2016).

\section{Materials and Methods}

The bone is the basic element of the vertebrate skeleton, characterized by its rugged, solid and resilient structure. The longest bone is the femur of the foot, usually over $50 \mathrm{~cm}$ and the small one is the "snout" in the ear. Between them, the bones bind through the joints and are mobilized by the muscles.

The number of bones decreases in humans by merging, with age, from 350 to a newborn to 206 in an adult. Besides, bone resistance is incredible. A 1centimeter bone cube would be able to support 1,733 kilograms, the weight of an adult male hippopotamus.

\section{Bone Composition}

The bone consists of $20 \%$ water and $80 \%$ dry residue. It is made up of a solid organic matrix that is strengthened by deposits of calcium salts.

\section{Organic Bone Matrix}

It is composed of $90-95 \%$ collagen fibers and the rest is a homogeneous environment called fundamental subsonic, together constituting the ossin. The collagen fibers extend first along the lines of the force and give the bone its high voltage-resistant. 


\section{Mineral Salts}

In particular calcium phosphate $\left(\mathrm{CaPO}_{4}\right)$ and the most important crystalline substance is hydroxyapatite $\left(\mathrm{Ca}_{5}\left(\mathrm{PO}_{4}\right)_{3} \mathrm{OH}\right)$.

Metabolic processes similar to the other organs occur in the bones. A metabolic particularity is the great affinity of the basic substance for mineral salts.

\section{Bone Structure}

The bone is made up of 2 types of tissue:

Compact bone tissue - the toughest tissue of the human body. The middle part of the long bone, called bone or diaphysis. On the outside there is a membrane, called periost, whose bone increases in thickness. Within the diaphysis we have a channel that runs through its length, called the medullary canal where the hematogenous marrow plays a role in the production of figurative blood (erythrocytes, leukocytes, platelets). It is worth mentioning that in the children all the bones produce this marrow and will have a red color, in the adult only the bones will be yellow and yellow and in the elderly will be gray-gray and will be dysfunctional.

Spongy bone tissue - a relatively light, less durable and resistant structure. Extremes of the long bone (also called tubular bone), called epiphyses. They are made up of $95 \%$ spongy bone tissue on the inside and $5 \%$ compact outer tissue. Between epiphysis and diaphysis is metaphysis, or epiphyseal-diaphysiular growth cartilage, on which long bone grows in length. Growth will be from epiphyses to diaphysis. The epiphyseal joint surface consists of a thin layer of hyaline cartilaginous tissue.

\section{Results}

How to build a healthy bone and the role of its new structures (Fig. 2)?

A bone is first produced from a cartilage. The cartilage then slowly transforms into a bone through a complex process. When a baby floats in his mother's womb, the developing organism begins to build its shape and causes the cartilage to do so. Cartilage is a tissue that is not as rough as bones but much more flexible and, in a way, more functional.

A large amount of fetal cartilage starts to turn into bone, the process itself is called ossification. When ossification takes place, cartilage (which does not contain salts or minerals in it) begins to calcify; that is, the layers of calcium and phosphate salts begin to accumulate on the cells of the cartilage slowly. These cells, surrounded by more and more minerals, aging and dying. This leaves some small pockets of separation in the modified cartilage and small blood vessels grow in these cavities. Now, some specialized cells called osteoblasts start traveling in the developing bone through these blood vessels. These cells produce a substance consisting of collagen fibers and also help in the collection of calcium that is deposited along this fibrous substance (A common analogy for this design is reinforced concrete, which is a network of metal bars coated with concrete mixture).

After a while, osteoblasts become part of the mixture, turning into inferior osteocytes, a retracted version of osteoblasts that continue to sneak but do not distance themselves too much from the blood vessels. This newly formed osteocyte network helps to form the sponge-like network of spongy bone. The oscillating bone is not soft, but looks spongy, meaning that it remains in its construction. These spaces help first of all to transfer the external pressure stress to the entire bone (distribution of external pressure on the entire surface of the bone) and secondly, these spaces also contain the marrow. Channel canals, called canaliculi, run on all calcified bone parts, allowing nutrients, gases, toxins and waste to pass through them (Fig. 3 and 4).

Marrow in the middle of a young man's bones is red and crossed by blood vessels (Fig. 3). Bone marrow to an adult bone grows yellow and has few blood vessels and at some point, it does not have any. In the elderly, the blood vessels from the bones disappear (Fig. 4).

An extremely interdisciplinary research group has been involved in the study of bone as living material. The main efforts have been made to imitate bone characteristics and the process of formation and behavior under physiological load (Apicella et al., 2010; 2011; 2015; Gramanzini et al., 2016; Kummer, 1986; Perillo et al., 2010).

Advanced academic studies on biomechanics and bone biomimetic implants have resulted from these investigations.

This work project identifies a number of design criteria to promote the potential of allowing new medical therapies to contribute to personalized healthcare and to create and improve the technological foundation for innovative prosthetic design.

The human femur is characterized by a specific internal structure (Oh and Harris, 1976; Gottesman and Hashin, 1980), which gives the bone a high capacity to withstand external stress, optimize mass distribution and morphology (Ashman et al., 1984; Dalstyra et al., 1993).

However, the physiological loss of bone mass appears progressively in the older age, reducing its strength and ability to dissipate the energy transmitted by the external shock event and this characteristic is the cause of most of the pertrochanteric fractures of the elderly along the plane indicated in Fig. 5.

Aversa et al. (2016a; 2016b; 2016c) successfully modeled this behavior. Pertrochanteric fractures require the application of hip joint prostheses (Burnstein et al., 1976; Carter and Hayes, 1977). Changing the biomechanical behavior of aged or implanted bones can be predicted correctly using previously developed FEM (Apicella et al 2010; Aversa et al., 2009). 


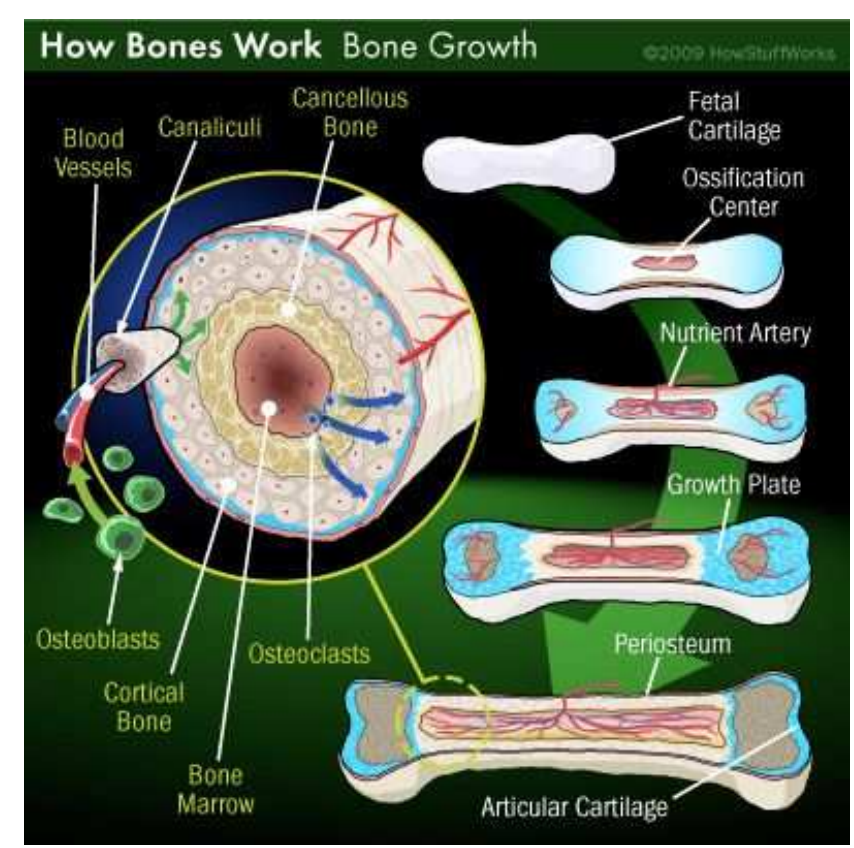

Fig. 2: How does bone grow and develop

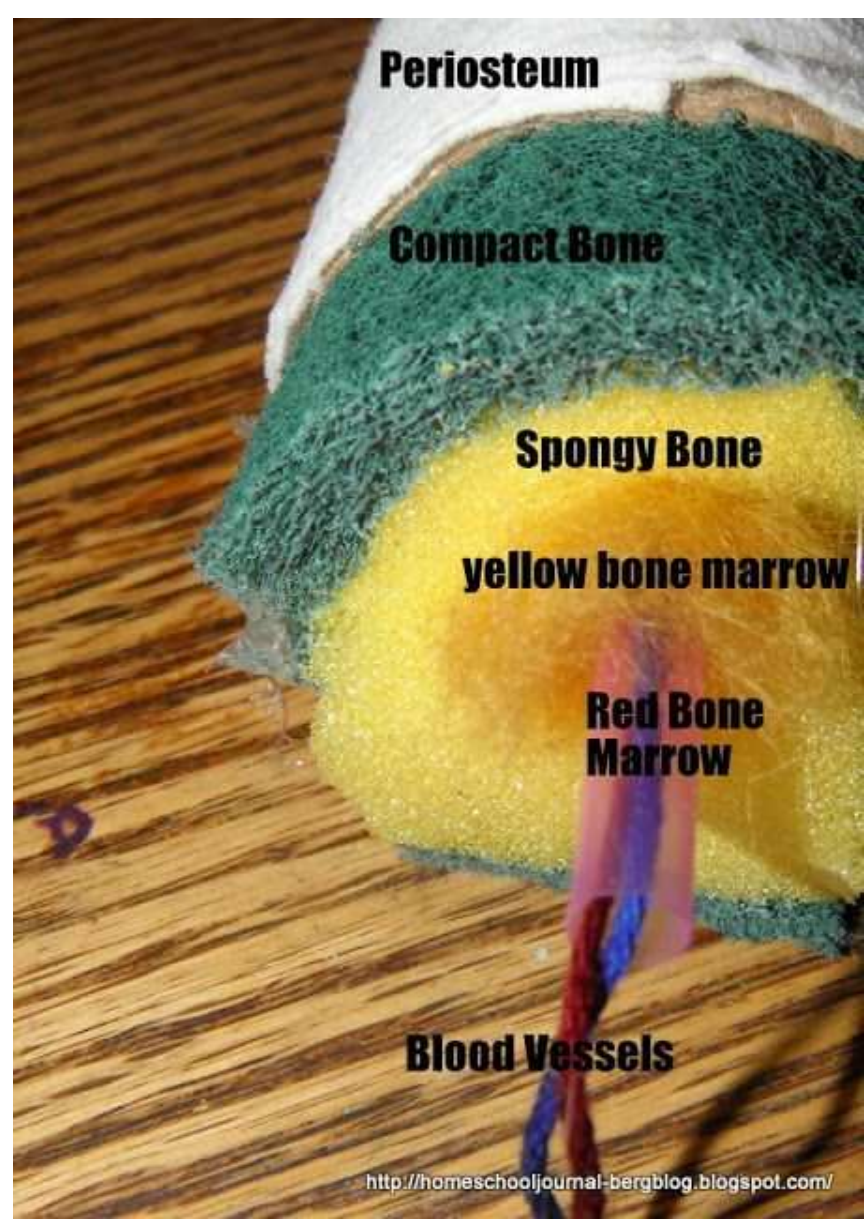

Fig. 3: The structure of a youngster's bone 


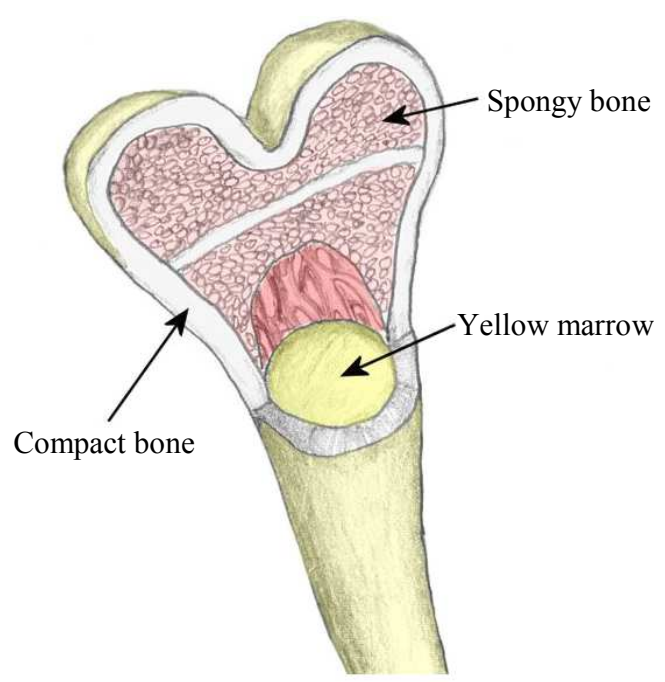

Fig. 4: Bone marrow to an adult bone grows yellow and has few blood vessels and at some point, it does not have any
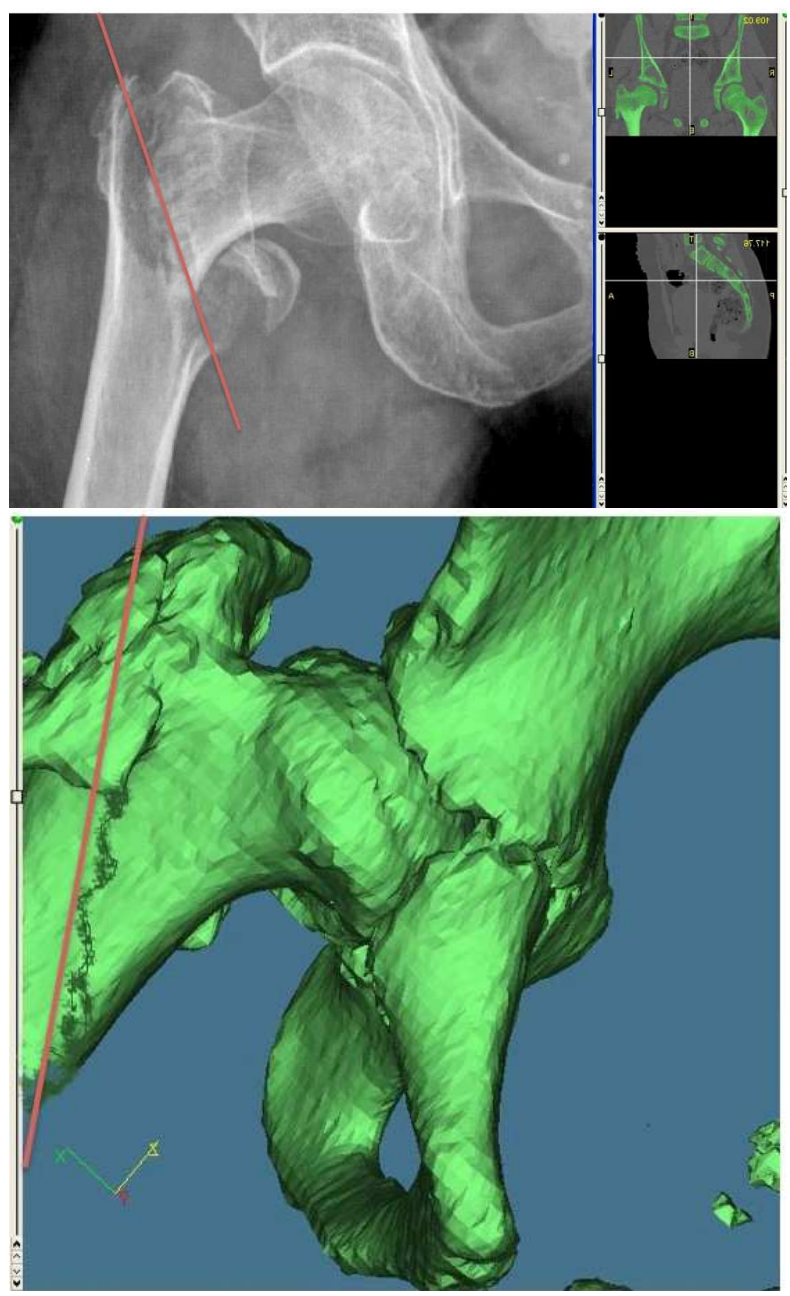

Fig. 5: Fracture planes (red line) of a pertrochanteric femur fracture (left CT) and solid modeling from software for CT segmentation in the proximal epiphysis - pelvis region
However, replacement of the total hip in patients under the age of 65 and therefore with the required prolonged durability of the orthopedic implant cannot last for more than 15 years.

However, this clinical scenario is changing now. More technological developments in health have increased life expectancy. In addition, the prognosis of physical trauma caused by sports, excessive exercise and excessive exercise or road accidents has improved. The new design then requires durable and biomechanically compatible prostheses.

The orthopedic prostheses used today are made of metal alloys, plastics and ceramics with well-defined properties and characteristics.

In particular, due to their high biocompatibility and high mechanical strength, the usual metal alloys are based on titanium or chromium cobalt and represent almost all the prosthetic components that are in direct contact with the human bone because they provide optimal components for bone integration.

Implant failures are mainly due to the biomechanical incompatibility between the prosthesis and the bone, i.e., the inadequate force or inadequate rigidity between bone and implant causes discontinuities in the distribution of stress and bone strains compared to biological ones.

Current implants (metallic and ceramic) that are more rigid than the bone significantly alter the distribution of physiological stress and prevent the transfer of stress to the adjacent bone (Apicella et al., 2010; 2011; 2015), resulting in bone reabsorption near the implant.

To predict the structural changes induced by the modification of bone morphological and mechanical characteristics, femoral models have been developed (Aversa et al., 2016a).

The development of these bio-models has already allowed us to predict strictly the physiological stress and strain distribution in mandibular and prosthetic implants (Apicella et al., 2010; Gramanzini et al., 2016; Perillo et al., 2010; Sorrentino et al., 2009; 2007).

This paper developed an FEM model that was developed in a previous paper to correctly represent the structural behavior of the head of the femur (Aversa et al., 2016a) for the distribution of stress and strains throughout the stem and head and was modified consider the resection and replacement of the femoral head with a Titan hip prosthesis in the case of pertrochanteric femur fracture (Fig. 5).

A comparison of the biologic stress and strain distribution in femoral and prominent femoral models could help to understand the correct design procedures needed to design new innovative biomimetic prostheses.

The CT-derived image segmentation was performed using the Mimics software (Materialize, Belgium) to process the patient's CT. A solid 3D solid model of the patient's and femoral pelvis anatomy, Fig. 6, was obtained by processing CT data. 
The design of new prostheses through a combined use of the Mimics and 3-Matic software (Materialalize, Belgium) could be derived from the biomechanics study of these bone raions. The combined model of solid modeling and finite element analysis were developed in an earlier work by Aversa et al (2016a).

These methods simulated the structural morphology of the femur as it was done for other complex bone structures, taking into account the trabecular bone orientation and densities (Apicella et al., 2010; 2011; 2015; Aversa et al., 2016a; 2016b; 2016c, 2009; Beaupre and Hayes, 1985; Reilly and Burstein, 1974; Reilly and Burstein, 1975; Huiskes et al., 1987; Taylor et al., 2007; Rohlmann et al., 1982).

Several recent studies have highlighted the importance of FEM analysis in clinical applications and the development of new prosthetic systems (Mirsayar and Park 2016; Mazaheri et al., 2016) and the use of innovative materials and surface treatments (Kumar et al., 2016). The methodological procedure is illustrated in Fig. 7 to 10. The external geometry of the femur and pelvis was remodeled, creating a $3 \mathrm{D}$ volume of CT scans (Fig. 7). The models were imported into the 3Matic software to create and optimize the surface and solid networks needed to prepare the finite element model and to designate the properties of the materials (Aversa et al., 2016a). The results of tethraedric element material distribution are shown in Fig. 8.

The same procedure has been applied to the preparation of the FEA model of the femur with the resection of the head (Fig. 9), which has been virtually related to the fracture plane reported in Fig. 5 and for the Titanium traditional hip-joint prosthesis (reported in the Left side of Fig. 10).

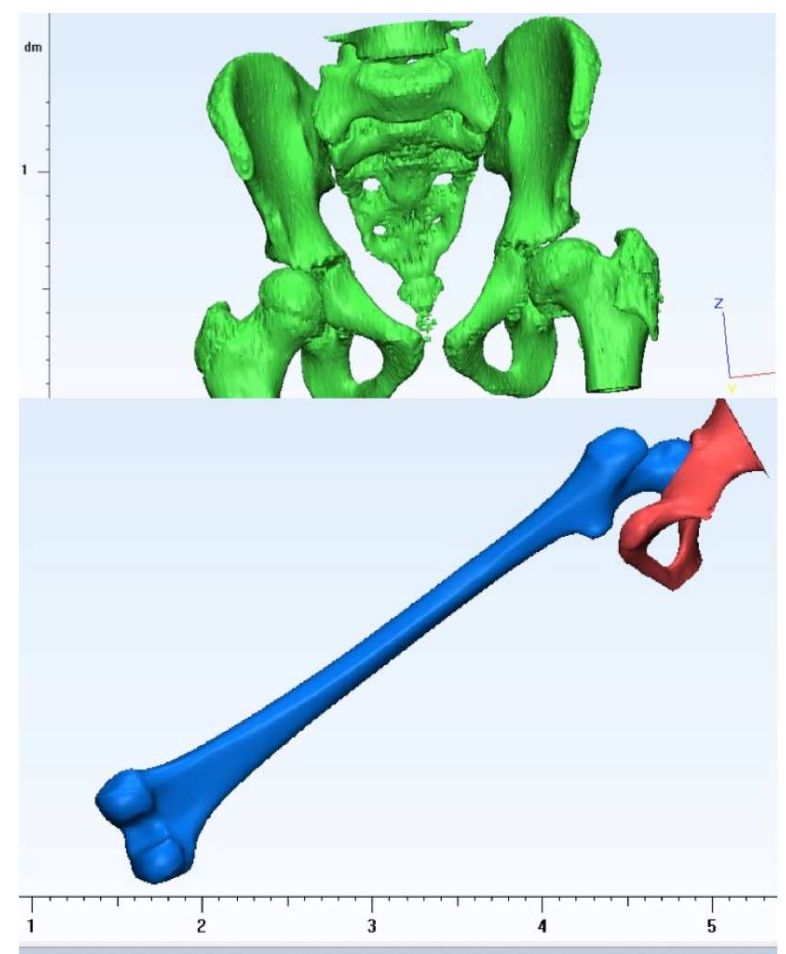

Fig. 6: Biofidel medical Image Segmentation of a patient pelvis and femur

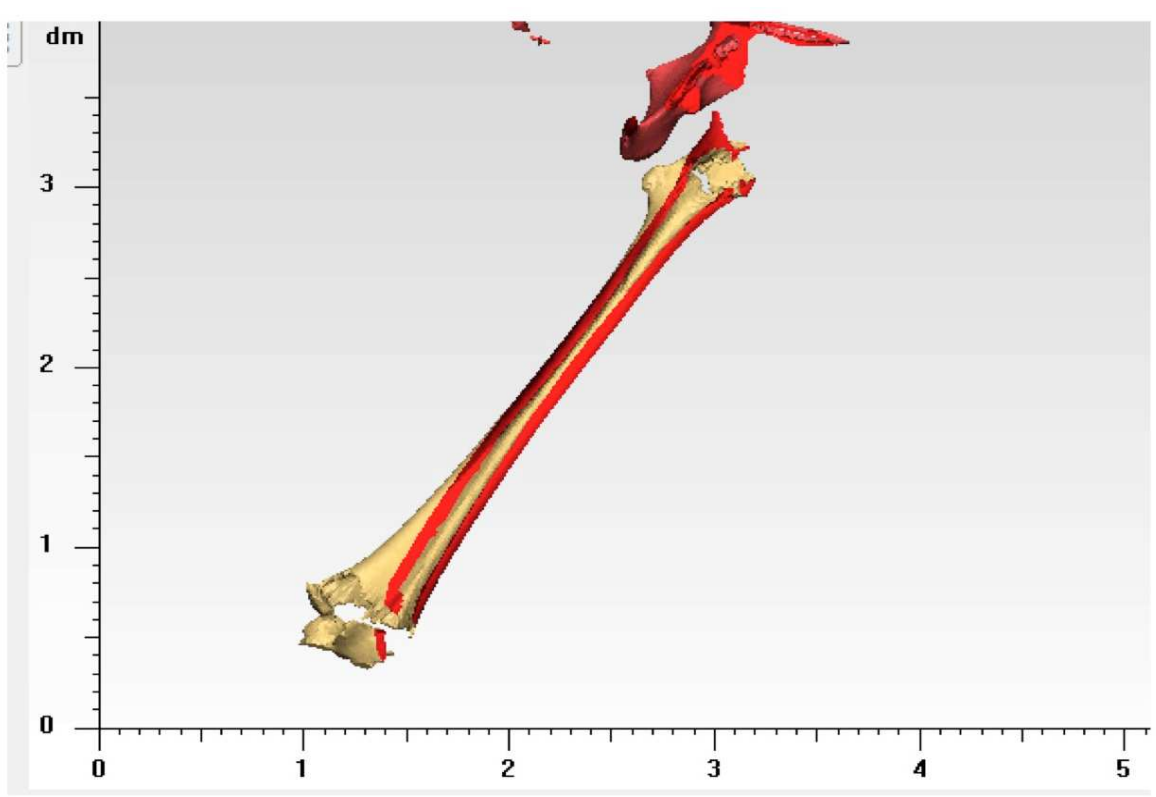

Fig. 7: Biofidel 3D solid modelling of a patient femur and pelvis 


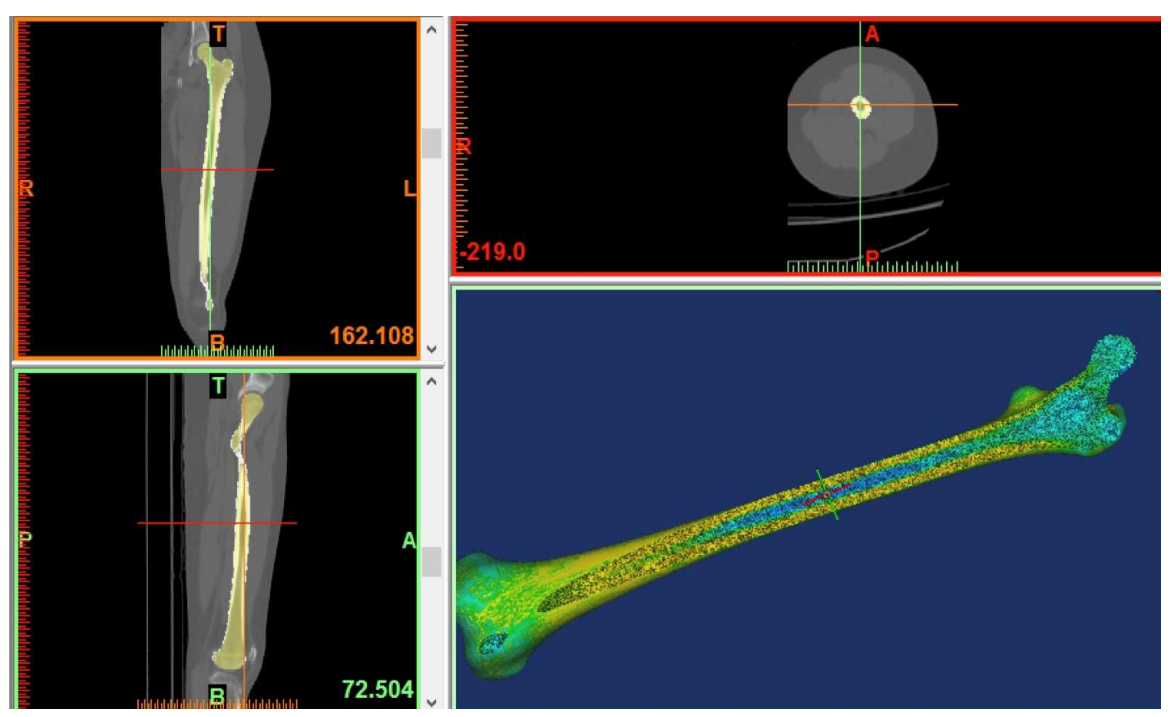

Fig. 8: Mesh creation and optimization of the biofidel not resected femur model (Aversa et al., 2016a)
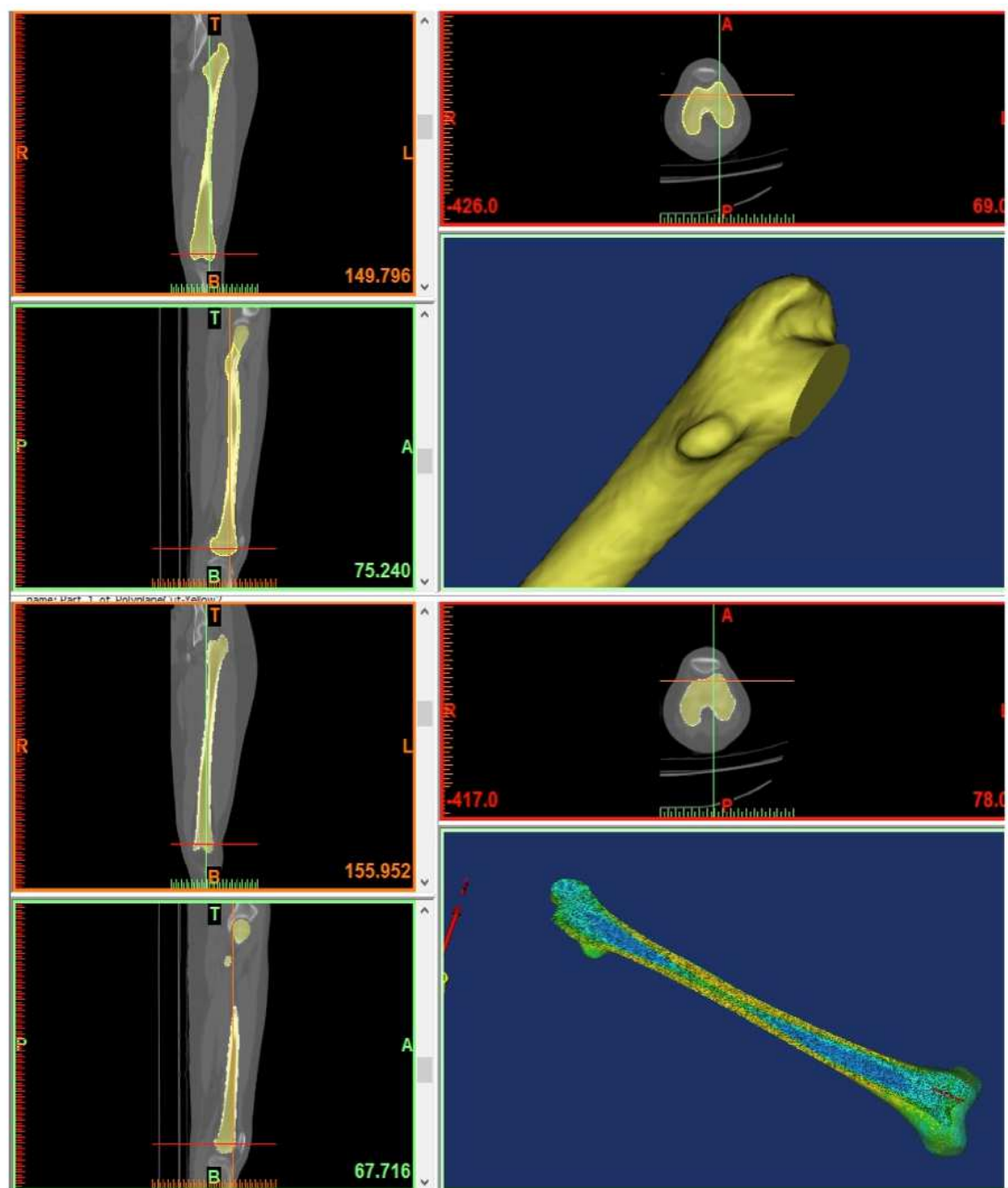

Fig. 9: 3D meshing optimization of the biofidel patient femur model 
The model of the resected femur and of the Titanium prosthesis has been realized by definition of the $3 \mathrm{D}$ tethraedric mesh optimization of the distribution and size, as indicated in the right side of Fig. 9 and in Fig. 10, respectively. The solid mesh elements of the resected femur have been associated to the bone densities such as measured by a Hounsfield (HU) scale, which compute the X-rays linear attenuation coefficients of in the tissues, by the Mimics software (lower part of Fig. 9). The evaluation of mechanical properties has been done considering the cortical and trabecular bone mechanical characteristics.

The meshed solid models of the resected femur and of the Ti prosthesis were assembled accounting to the correct positioning of the implant using the Mimics software (Fig. 11).

New remeshing of the tethraedric elements were run in 3 Matic (Fig. 12) searching for the node congruency at the bone-implant interfaces, where the material definition has been made for the new finite elements configuration.

In the Hounsfield (HU) scale, the trabecular bone is in the range 100-300, while the cortical bone covers values from 200 up to about 2000, which corresponded in our bone systems to Elastic moduli ranging from 0,87 to $15.0 \mathrm{GPa}$. The fat value is about -110 , the muscle about 40. Finally, the mechanical properties of the prosthesis Ti alloy are: Elastic modulus equals to 124 GPa and Poisson ratio 0.3.

\section{FEM Analysis: Sound and Prosthesis Femur}

On the basis of the 3D models of the sound femur and the resected femurs implanted with a traditional rigid prosthesis, a structural evaluation under the same loading conditions has been developed and the results critically compared. The personal characteristic biometric parameters of the patient femur-hip system have been carried out before running the structural analysis.
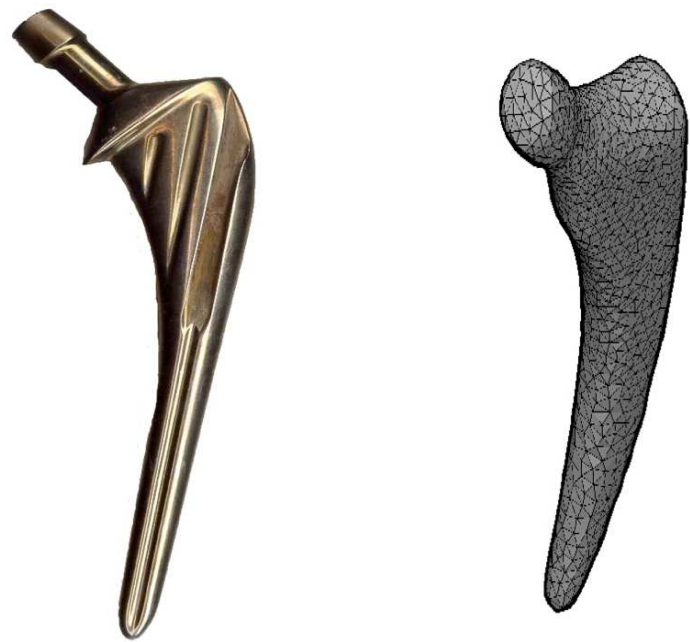

Fig. 10: 3D meshing optimization of a Titanium traditional prosthesis

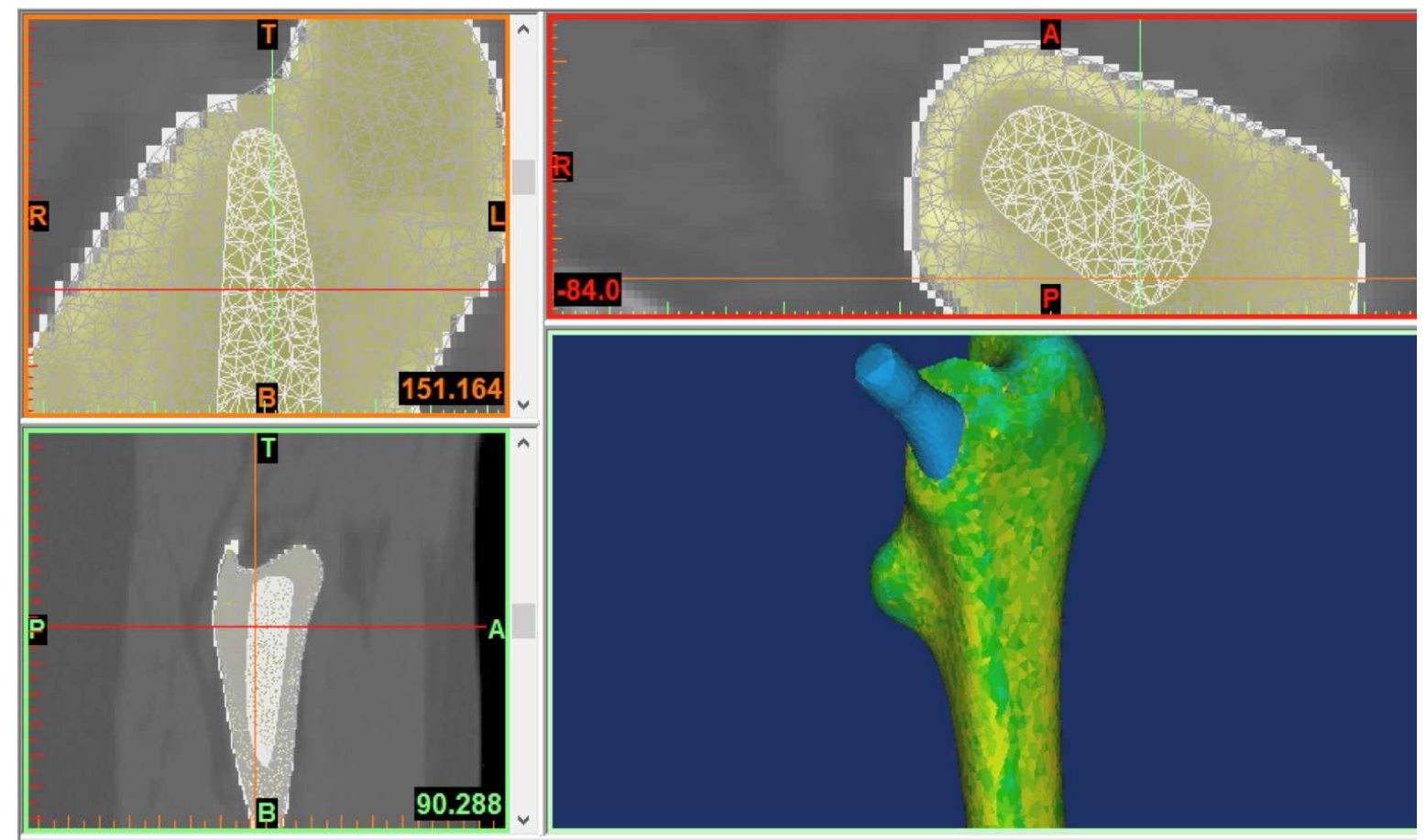

Fig. 11: Assembly and material properties definition associated to the patient femur cortical and trabecular bone densities and to the Titanium prosthesis 


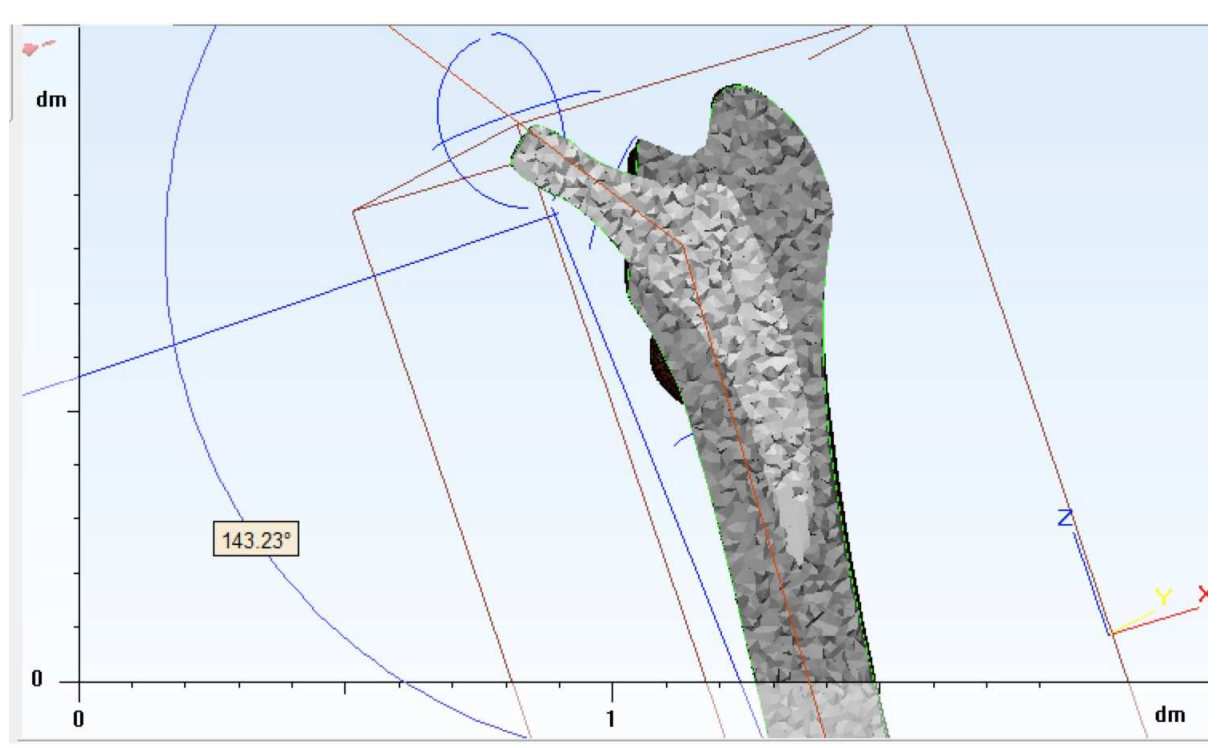

Fig. 12: Assembly of the resected femur and Titanium rigid hip prosthesis and tetrahedral mesh congruence verification

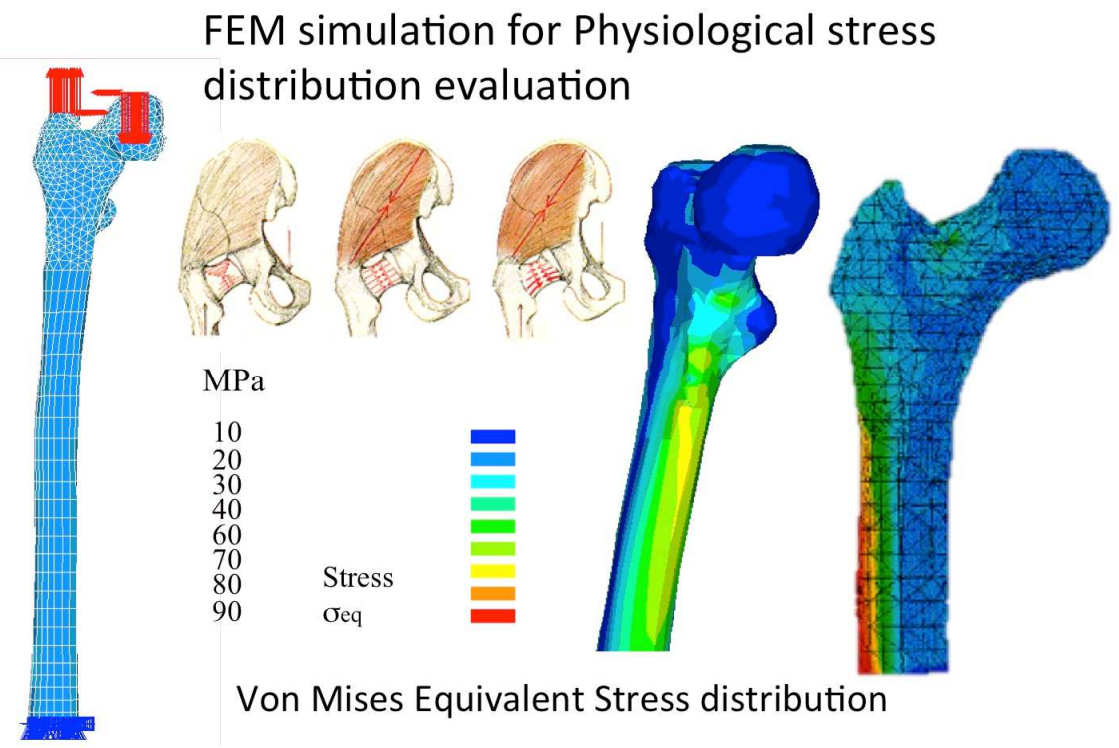

Fig. 13: Physiological Equivalent Von Mises stresses in the femur from our bio fidel Finite Element Model

The 3Matic software has been used to identify the direction of the loading axis, the center of the proximal epiphysis head sphere and the center of the joint epicondyle and mechanical axis of rotation of the knee. Namely, the following parameters have been measured: The mechanical axis between the centers of the proximal and distal epiphyses, the angle of $143.40^{\circ}$ between the femoral neck and diaphysis axes and the divergence of $36.65^{\circ}$ between the neck axis with the axis of epicondyles. Finally (before running the FEM structural analyses) the physiological loads and constrains have been evaluated. As limiting bone load condition, the equilibrium monopodalic posture has been chosen where the gluteus muscular force balances the moment of body weight force. For a body weight of $100 \mathrm{Kg}$ and accordingly to the previously defined biometric parameters, the gluteus muscular force applied to the great trochanter is about $1800 \mathrm{~N}$ and the reaction force at the joint 2740 N. (Kumar et al., 2016; Annunziata et al., 2006). The equilibrium condition and femur-loading scheme are illustrated in Fig. 13. Reaction forces generated by the gluteus have been uniformly distributed over 100 nodes of great trochanter surface. The reaction forces acting at level of the femur joint are distributed on 50 nodes of the femur head (as indicated in the upper left of Fig. 13). 


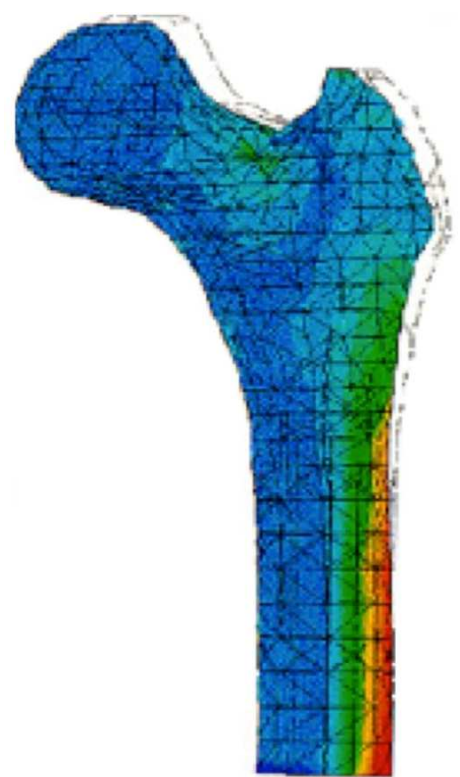

(a)

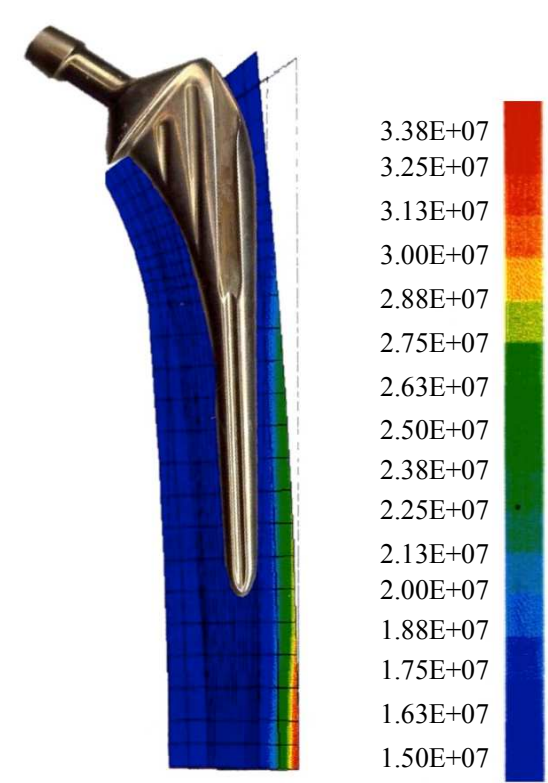

(b)

Fig. 14: Equivalent Von Mises stresses distribution in the proximal femur epiphysis for (a) sound femur, (b) rigid Ti prosthesis

This study defines a biofidel model to investigate the femur structural behavior. Von Mises strain criterion has been used to compare the stress distributions in sound and prosthesis femur under the previously defined loading conditions. This Von Mises is an energetic criterion that can better quantify the capability of the sound femur to withstand high loads (right part of Fig. 13). Posteriorly, stress distribution confirms the presence of bending effects, with the highest values homogeneously distributed in the anatomical diaphysis regions (right hand side of Fig. 13) with a maximum of about $90 \mathrm{MPa}$. The same structural analysis has been carried out on the on the FE model of the prosthesized femur described in Fig. 11 and 12. The results of the analysis are compared in Fig. 14 to those evaluated for the sound femur. Figure 14 shows the significant alteration of the stress distribution in the sound femur (left hand side) and the resected femur with the rigid Ti prosthesis (right hand side).

\section{Discussion}

The bones, or skeleton, have several functions:

Leverage role of the locomotive device. They act on their muscles, ensuring body support and locomotion. It is thus constituted as levers of three orders:

1. The spine of the skull

2. The joint between the bones of the leg and the leg

3. The joint between the arm and the forearm.

\section{Protection Role of Vital Organs}

- The skull box for the encephalus
- Spinal cord spinal canal

- Chest box for heart and lungs

- Bone pelvis for pelvic organs

\section{Antitoxic Role}

The bones contain many toxic substances $(\mathrm{Hg}, \mathrm{Pb}, \mathrm{F})$ accidentally penetrated into the body and release them gradually and then renal elimination. In this way, the blood concentration of the toxin does not increase too much and the harmful effects on other organs are prevented.

\section{Main role of Hematopoietic Organs}

o In the bones, all the bones and in adult bones the bones contain red, haematogenic marrow. In adults, the marrow from the central bony diaphysis of the long bones is yellow (adipose tissue with a spare role) and in the elderly it is gray, dysfunctional.

\section{Role in the Metabolism of Calcium, Phosphorus and Electrolytes}

Bones are the main body of mineral substances in the body.

The bones are a composite material consisting of a rigid and fragile inorganic component (hydroxyapatite) and an elastic collagen matrix.

The smoother organic component is larger in children and therefore less rigid and is prone to slipping under the load (the organic component where the bone growth mechanisms are found to be characterized by viscoelastic behavior). This is an advantage for young bones (boys for small children) because they do not easily break 
under a shock load, however they easily deform into continuous tasks. With increasing age, the amount of collagen decreases with bone stiffness and strength, but becomes more fragile and fractures.

In young bones, its behavior should be considered viscoelastic and resistant, while in the elderly it should be considered elastic and fragile.

Yes, the properties of bone materials are different for both the child and the elderly man. In simple words, you can say that bone mineral density is higher for children and reduces according to age. As we get older, the mineral density of the bones decreases. Dependence of bone mineral density is on many factors such as age, gender, geographical conditions, food behavior, posture, etc.

The inorganic phase or mineral phase is composed mainly of hydroxyapatite, whereas type I collagen, noncollagen proteins, other components and water comprise the modification of the organic Bone Mineral Density (BMD) phase is very important, currently measured by a technique such as would be scanning DEXA and spin X radiographs. By aging, a bone can lose density, which defines osteoporosis when density falls to some limits. The content of collagen in the cancellous bone can decrease both by aging and illness. Power plays an important role here, but also the existence of an active, dynamic life regime that encompasses daily movement over long distances. Lack of motion together with an unhealthy diet certainly leads to illness bones, with serious consequences for the health of the whole organism.

\section{Bone Diseases}

Deformations: Can occur at the level of any component of the bone system. The most common are those of the spine: Chest, lordosis and scoliosis.

Ciposis represents an exaggeration of the spine curvature at thoracal and sacral level. Seen in a sagittal plane, the concavity will look before.

Lordship is an exaggeration of the curvature of the spine at the cervical or lumbar level. Seen in the sagittal plane, the concavity will look behind you.

Scoliosis is an exaggeration of the lateral curvature of the spine and can occur at any level. Viewed in the front plane, the curvature will have a lateral direction (left or right).

Fractures: Defined as an interruption of the anatomical continuity of a bone. Usually, they come from traumas, but also from hormonal deficiencies or diseases, when they can be spontaneous.

Entrails: Are defined by elongation of the component ligaments of a joint as well as the proximal ligaments. They can have varying degrees of severity. It is often associated with synovitis.

Lids: Define as the dislocation of the component elements of a joint, especially of the joint surfaces. The most common is the swelling of the shoulder and knee joints.
Arthritis: Defined as joint disorders with symptoms such as edema, inflammation and pain. More than 50 joint disorders, widely called "rheumatic diseases", are known. The causes of most arthritis are unknown, but many of them arise from traumas or infectious processes.

Bones can become more fragile and can break more easily in the absence of certain nutrients in the body. For bone strengthening and protection against osteoporosis, the following foods containing the most important nutrients are recommended.

From calcium or magnesium to potassium or vitamin $\mathrm{C}$, a number of nutrients are needed for the body for good bone strength. However, the most important thing is knowing what foods the body can extract these nutrients so necessary.

\section{Calcium}

When it comes to preventing osteoporosis or treating it, calcium is one of the most important nutrients for the bone. Ideally, we accumulate 1,000-1,300 mg of calcium per day from the foods we eat. The most recommended are plain, non-fat, low fat or low-fat milk, cheeses, tofu, soy, white beans, cabbage, broccoli or almonds.

\section{Vitamin D}

Another vital nutrient for bone health is vitamin D. Even for the accumulation of calcium in the body vitamin $\mathrm{D}$ is needed. The body can produce vitamin D with sunlight, but the best sources remain vitamin D foods and supplements. Fatty fish, such as salmon, herring, mackerel or sardines, is an excellent source. Milk, yogurt and mushrooms and egg yolks are rich in this vitamin.

Protein Studies have shown that lack of protein in the body leads to accelerated bone loss. Proteins are very important in the recovery process of injured bones. However, large amounts of protein can be harmful, so the most recommended foods, consumed in moderate amounts, are the lean meat of turkey, chicken, beef or pork, seafood, egg whites, dairy products with little fat, legumes or even peanut butter.

\section{Magnesium}

Several studies have concluded that this mineral can play a very important role in the prevention and treatment of osteoporosis. Magnesium helps the body neutralize metabolic acids, helps absorb calcium and maintains the strong bone structure. Magnesium is found in pumpkin seeds, brown rice, spinach, agar, sweet potatoes, beans, sesame or flax seeds.

\section{Potassium}

Many fruits and vegetables contain significant amounts of nutrients, including potassium. A diet rich in 
potassium helps to slow down the decline in bone mineral density that occurs with aging. Bones can be kept as strong by eating melons or apricots, papaya, bananas, plums, raisins, avocados, artichokes, lettuce, carrots, tomatoes, beans, almonds or pistachio.

\section{Vitamin K}

This vitamin is essential for the formation of osteocalcin, a type of protein found only in the bones. High intake of vitamin $\mathrm{K}$ leads to a lower risk of fractures. Therefore, it is recommended to consume the food where this vitamin can be found. The most common is contained in greens such as lettuce, spinach, asparagus, broccoli, Brussels sprouts, parsley.

\section{Vitamin $C$}

Consumption of foods rich in vitamin $\mathrm{C}$ allows the body to produce enough collagen, a protein that contributes to bone strength. It is not very difficult to obtain the necessary amount of vitamin $C$ if you are a fan of strawberries, oranges, lemons but also frequently eat cabbage, cauliflower, tomato, horseradish.

\section{Soy}

To give bone mineral density a boost of protein, try to eat soy foods several times a week. Some studies suggest that soy foods can help slow down bone loss and prevent fractures.

Compared to the physiological flexural stresses in the diaphysis of the sound femur, the prosthesized femur induces a concentration in the medial region while they are completely absent in the proximal end. This occurrence is referred as "stress shielding effect" and it is due to the high rigidity of the metal prosthesis stem that does not allow the physiological flexure of diaphysis.

The absence of stress (and related strains state) could induce, over the time, significant bone structure modification (bone reabsorption).

Bone modeling and remodeling processes, in fact, enable itself to grow, renew and repair itself (Gottesman and Hashin, 1980; Huiskes et al., 1987; Taylor et al., 2007; Weinans et al., 1992). Mechanical adaptation of trabecular density and architecture could be explained in terms of mechano-sensory and signaling functions for the osteocytes (Mullender and Huiskes, 1995). Mechanic-regulation mechanism driving bone remodeling uses mechanical strain and micro-damage as the stimulus driving cellular responses and the consequent changes in the bone density and geometry. The absence or the modification of the biomechanical stimuli shown in Fig. 10 for the femur diaphysis after prosthesis implantation is then expected to lead, over the time, to a bone remodeling and reabsorption due to the absence of an adequate stress and strain state.

\section{Conclusion}

The bones contain red, haematogenic marrow. In adults, the marrow from the central bony diaphysis of the long bones is yellow (adipose tissue with a spare role) and in the elderly, it is gray, dysfunctional.

The bones are a composite material consisting of a rigid and fragile inorganic component (hydroxyapatite) and an elastic collagen matrix.

The smoother organic component is larger in children and therefore less rigid and is prone to slipping under the load (the organic component where the bone growth mechanisms are found to be characterized by viscoelastic behavior). This is an advantage for young bones (boys for small children) because they do not easily break under a shock load, however they easily deform into continuous tasks. With increasing age, the amount of collagen decreases with bone stiffness and strength, but becomes more fragile and fractures.

In young bones, its behavior should be considered viscoelastic and resistant, while in the elderly it should be considered elastic and fragile.

By aging, a bone can lose density, which defines osteoporosis when density falls to some limits. The content of collagen in the cancellous bone can decrease both by aging and illness. Power plays an important role here, but also the existence of an active, dynamic life regime that encompasses daily movement over long distances. Lack of motion together with an unhealthy diet certainly leads to illness bones, with serious consequences for the health of the whole organism.

Results of our biofidel modeling of the sound and prosthesized bone would clarify the level of complexity needed when computing the strain state of a human femur through FEA when the stress and strain state has to be used to quantify the bone remodeling process.

A faithful bone models allows the accurate choice of the femur locations where the hypothesis of isotropic conditions (diaphysis) can be made and the femur locations where the bone orthotropy hypothesis should be applied (proximal end epiphysis). The distribution of maximum strain is correctly described by our theoretical approach since can envisage the location of the pertrochanteric fracture. The model can be usefully applied in those cases where the strain distributions need to be evaluated in order to predict undesired bone remodeling processes.

A further field of application of the product is surgical new prostheses design for orthopedic oncology to support and facilitate bone regeneration resulting in massive losses due to interventions of removal of both primitive and metastatic tumors.

The prosthetic system could be redesigned to a better functional recovery by promoting bone recreation by bone growth stimulation while ensuring a good hold of the load. 
These improvements of the system biomimetic characteristics positively impact on the quality of life of the individual patient, which was already seriously compromised by the basic oncological pathology.

\section{Special Discussion}

The bone is still a great enigma, as it is structured, in terms of its growth and then decay, as well as all its functionalities.

The authors believe that here is a key that could open our door to improving and prolonging human life.

The main function of the spine is not supportive, but a more hidden one, namely to produce fresh blood with its main red and white cells, playing essential roles in supporting the life of the body.

Erythrocytes are also known as red blood cells. There are nucleated cells that are found in blood, rich in hemoglobin. Hemoglobin is a red protein with a role in the transport of oxygen and carbon dioxide.

Erythrocytes are the most numerous elements in the blood. The blood contains about 4 million and a half of the woman's liver and 5 million in a man's only one cubic millimeter. For the younger the number of erythrocytes is higher, up to 6 million per cubic millimeter and for the inhabitants of the high altitude areas the number of erythrocytes can reach up to 8 million per cubic millimeter due to adaptive mechanisms to cope with low oxygen concentrations. The number of erythrocytes may temporarily increase when the blood deposits of the spleen and liver are released.

Erythrocytes are formed in the haematogenous marrow.

The number of erythrocytes may fall by two major mechanisms: Decreased medullary production or higher destruction in the periphery.

The process of formation of erythrocytes is called erythropoiesis. The most important hormone that causes erythropoiesis is erythropoietin, secreted in the kidney. It secretes erythropoietin under physiological conditions and secretion is increased in hypoxia conditions. The erythropoiesis process requires nutrients, vitamins $(\mathrm{C}$, B6, B2, folic acid) and iron.

Hemata have two essential roles for the body:

Carrying oxygen and carbon dioxide from lungs to tissues and vice versa.

White blood cells, also known as white blood cells, are the figurative elements of the blood that possesses the nucleus. Their number averages 5,000 per cubic millimetre (ranging from 4,000-8,000/cubic millimeter). These values may vary in physiological or pathological conditions.

Increased white blood cell counts are called leukocytosis and decreased leukopenia. Physiologically, in the physical effort we have a discreet leukocytosis and after a prolonged rest a slight leucopenia. Pathological variations are much greater. In microbial infectious diseases, the number of leukocytes may increase to 15,000-30,000/cubic millimeter, sometimes even more and in some cancers, such as leukemia, their number may exceed several hundreds of thousands per cubic millimeter and the blood gets a whitish color (white blood).

There are several types of white blood cells. All types of leukocytes interfere at various levels in defending the body against various pathogens.

Percent expression of different types of white blood cells is called the leukocyte formula. Within this formula, we distinguish single nucleotide leukocytes, called mononuclear and polylobate fragmented nucleotides, called polynuclear.

Mononuclear cells represent about one-third of leukocytes. The mononuclear group comprises lymphocytes and monocytes.

Polynuclears represent about two-thirds and comprise 3 cellular subgroups. Polynuclears are also called granulocytes, following the granulations observed in their cytoplasm. The polynuclears are divided into:

a. The most numerous neutrophil polinuclears - are stained well with neutral dyes - are also called polymorphonuclear neutrophils

b. Polynuclear eosinophils - granulations are well colored with acidic dyes

c. Polynuclear basophils - are the least numerous have granularity of affinity for basic dyes.

The leukocyte size ranges from 6 to 8 microns for lymphocytes and 20 microns in diameter for monocytes and neutrophils.

Life span for leukocytes varies greatly, from 1 to 2 days for neutrophil polynuclears, up to a few years for thymus-dependent lymphocytes ( $\mathrm{T}$ lymphocytes). The process of leukocyte formation is called leukopoiesis. All white blood cell elements are formed in the haematogenous bone marrow. Leukopoiesis is regulated by complex neuro-humoral mechanisms. The centers of leukopoiesis are located in the hypothalamus. The activity of these centers intensifies when blood levels of nucleic acids resulting from the destruction of old leukocytes increase in blood.

The role of leukocytes is complex and different depending on their type:

a. Neutrophil Polymorphonuclears - accounts for about $55 \%$ of total leucocytes - they have a role of defense against bacteria in particular and they are phagocytes. Neutrophil polynuclears have the ability to elicit extensions, called pseudopods, can pass through capillaries into tissues, called diapedesis and migrate into tissues to infected outbreaks, a process called chemotactism

b. Lymphocytes - represents about $30 \%$. There are two main classes of lymphocytes: B lymphocytes (who 
participate in humoral immunity when antibodies are synthesized) and $\mathrm{T}$ lymphocytes (which have complex roles, from destroying other cells to immune coordination roles)

c. Monocytes - represents about $10 \%$. Monocytes are considered cells in transit through the blood, leave the capillaries and turn into macrophages, cells with important physiological roles and in immune defense

d. Eosinophils - about 4\% - play a role in defending against parasites

e. Bazophiles - about $1 \%$ - are important cells in the inflammation process

\section{Final Conclusion}

More recently was found that, stem cells that are so necessary to the body that they can regenerate all types of human cells, are also made in the spinal cord, which further increases its importance.

The vast majority of bones, in young and adult organisms, play a role similar to that of the spinal cord, producing red, white and perhaps stem cells. With the aging of the body, the bones begin to produce fewer such cells and at some point they do not manufacture them anymore.

Some of the bones lose their ability to manufacture these vital cells for the body as they age and at one point all bones become incapable of manufacturing something and they don't future support the vital functions of the spinal cord. This is the time when the human body cannot regenerate enough vital cells that basically give water, minerals, oxygen, food, energy, development and defense to all the cells of the body and there is no longer enough stem cells, so the body no longer has enough natural means of recovering the various altered tissues.

If we could prolong the life and functionality of human bones, we could thus improve and even prolong the life of man, but at the same time to redistribute his energy, vigor and health.

\section{Acknowledgement}

The Authors acknowledge Liquid Metals Technologies Inc, Ca USA that kindly supplies the samples for the characterization and Dream Laboratory (Virginia Tech, VA, USA).

\section{Funding Information}

This research has been funded by Italian Ministry of University and Research project FIRB Future in Research 2008, project RBFR08T83J.

\section{Author's Contributions}

All the authors contributed equally to prepare, develop and carry out this manuscript.

\section{Ethics}

This article is original and contains unpublished material. Authors declare that are not ethical issues and no conflict of interest that may arise after the publication of this manuscript.

\section{References}

Annunziata, M., R. Aversa, A. Apicella, A. Annunziata and D. Apicella et al., 2006. In vitro biological response to a light-cured composite when used for cementation of composite inlays. Dental Mater., 22: 1081-1085. DOI: 10.1016/j.dental.2005.08.009

Apicella, D., R. Aversa, E. Ferro, D. Ianniello and A. Apicella, 2010. The importance of cortical bone orthotropicity, maximum stiffness direction and thickness on the reliability of mandible numerical models. J. Biomed. Mater. Res., 93: 150-163. DOI: $10.1002 / \mathrm{jbm} . b .31569$

Apicella, D., M. Veltri, P. Balleri, A. Apicella and M. Ferrari, 2011. Influence of abutment material on the fracture strength and failure modes of abutmentfixture assemblies when loaded in a bio-faithful simulation. Clin. Oral Implants Res., 22: 182-188. DOI: $10.1111 /$ j.1600-0501.2010.01979.x

Apicella, D., R. Aversa, M. Tatullo, M. Simeone and S. Sayed et al., 2015. Direct restoration modalities of fractured central maxillary incisors: A multi-levels validated finite elements analysis with in vivo strain measurements. Dental Mater., 31: e289-e305. DOI: 10.1016/j.dental.2015.09.016

Ashman, R.B., S.C. Cowin, W.C. Van Buskirk and J.C. Rice, 1984. A continuous wave technique for the measurement of the elastic properties of cortical bone. J. Biomechan., 17: 349-361. DOI: 10.1016/0021-9290(84)90029-0

Aversa, R., D. Apicella, L. Perillo, R. Sorrentino and F. Zarone et al., 2009. Non-linear elastic threedimensional finite element analysis on the effect of endocrown material rigidity on alveolar bone remodeling process. Dental Mater., 25: 678-690: DOI: $10.1016 /$ j.dental.2008.10.015

Aversa, R., F.I.T. Petrescu, R.V. Petrescu and A. Apicella, 2016a. Biomimetic FEA bone modeling for customized hybrid biological prostheses development. Am. J. Applied Sci., 13: 1060-1067. DOI: 10.3844/ajassp.2016.1060.1067

Aversa, R., F.I.T. Petrescu, R.V. Petrescu and A. Apicella, 2016b. Biofidel FEA modeling of customized hybrid biological hip joint prostheses, Part I: Biomechanical behavior of implanted femur. Am. J. Biochem. Biotechnol., 12: 270-276. DOI: 10.3844/ajbbsp.2016.270.276 
Aversa, R., F.I.T. Petrescu, R.V.V. Petrescu and A. Apicella, 2016c. Biomimetic finite element analysis bone modeling for customized hybrid biological prostheses development. Am. J. Applied Sci., 13: 1060-1067. DOI: 10.3844/ajassp.2016.1060.1067

Aversa, R., D. Parcesepe, R.V. Petrescu, G. Chen and F.I.T. Petrescu et al., 2016d. Glassy amorphous metal injection molded induced morphological defects. Am. J. Applied Sci., 13: 1476-1482.

DOI: 10.3844/ajassp.2016.1476.1482

Aversa, R., R.V. Petrescu, F.I.T. Petrescu and A. Apicella, 2016e. Smart-factory: Optimization and process control of composite centrifuged pipes. Am. J. Applied Sci., 13: 1330-1341.

DOI: 10.3844/ajassp.2016.1330.1341

Aversa, R., F. Tamburrino, R.V. Petrescu, F.I.T. Petrescu and M. Artur et al., 2016f. Biomechanically inspired shape memory effect machines driven by muscle like acting NiTi alloys. Am. J. Applied Sci., 13: 1264-1271. DOI: 10.3844/ajassp.2016.1264.1271

Aversa, R., F.I.T. Petrescu, R.V.V. Petrescu and A. Apicella, 2016g. Flexible stem trabecular prostheses. Am. J. Eng. Applied Sci., 9: 1213-1221. DOI: 10.3844/ajeassp.2016.1213.1221

Aversa, R., R.V.V. Petrescu, A. Antonio and F.I.T. Petrescu, 2016h. Physiologic human fluids and swelling behavior of hydrophilic biocompatible hybrid ceramo-polymeric materials. Am. J. Eng. Applied Sci., 9: 962-972.

DOI: 10.3844/ajeassp.2016.962.972

Aversa, R., R. Sorrentino and A. Apicella, 2016i. Biomechanically active ceramic-polymeric hybrid scaffolds for tissue engineering. Proceedings of the International Conference on Biological Sciences and Technology, (BST' 16), Atlantis Press, pp: 308-318.

Aversa, R., R.V.V. Petrescu, A. Apicella and F.I.T. Petrescu, 2017a. Nano-diamond hybrid materials for structural biomedical application. Am. J. Biochem. Biotechnol., 13: 34-41.

DOI: 10.3844/ajbbsp.2017.34.41

Aversa, R., D. Parcesepe, R.V. Petrescu, F. Berto and G. Chen et al., 2017b. Processability of bulk metallic glasses. Am. J. Applied Sci., 14: 294-301.

DOI: 10.3844/ajassp.2017.294.301

Aversa, R., R.V. Petrescu, A. Apicella and F.I.T. Petrescu, 2017c. Modern transportation and photovoltaic energy for urban ecotourism. Transylvanian Rev. Admin. Sci., 13: 5-20.

DOI: $10.24193 /$ tras.SI2017.1

Aversa, R., R.V. Petrescu, F.I.T. Petrescu and A. Apicella, 2018. Nanodiamond for structural biomimetic scaffolds. MSCE, 6: 6-17.

DOI: $10.4236 / \mathrm{msce} .2018 .64002$
Beaupre, G.S. and W.C. Hayes, 1985. Finite Element Analysis of a three dimensional open-celled model for trabecular bone. J. Biomech. Eng., 107: 249-56. PMID: 4046566

Elena, B., 1976. Comparative study in the cordata series. Didactic Pedagogical Ed., Bucharest.

Burnstein, A., D.T. Reilly and M. Martens, 1976. Aging of bone tissue: Mechanical properties. J. Bone Joint Surgery, 58: 82-86.

Carter, D.R. and W.C. Hayes, 1977. The compressive behavior of bone as a two-phase porous structure. J. Bone joint Surgery, 59A: 954-962. PMID: 561786

Dalstyra, M., R. Huiskes, A. Odgaard and L. Van Erning, 1993. Mechanical and textural properties of Pelvic Trabecular Bone. J. Biomechan., 26: 349-361. DOI: 10.1016/0021-9290(93)90014-6

Duerig, T.W., 1990. Engineering Aspects of Shape Memory Alloys. 1st Edn., Butterworth-Heinemann, London, England, ISBN-10: 0750610093, pp: 499.

Gottesman, T. and Z. Hashin, 1980. Analysis of viscoelastic behaviour of bones on the basis of microstructure. J. Biomechan., 13: 89-96: DOI: 10.1016/0021-9290(80)90182-7

Gramanzini, M., S. Gargiulo, F. Zarone, R. Megna and A. Apicella et al., 2016. Combined microcomputed tomography, biomechanical and histomorphometric analysis of the peri-implant bone: A pilot study in minipig model. Dental Mater., 32: 794-806.

DOI: $10.1016 /$ j.dental.2016.03.025

Hanlon, J.E., S.R. Butler and R.J. Wasilewski, 1967. Effect of martensitic transformation on the electrical and magnetic properties of NiTi. Trans. Metallurgical Society AIME, 239: 1323-1327.

Harrison, J.D. and D.E. Hodgson, 1975. Use of TiNi in Mechanical and Electrical Connectors. In: Shape Memory Effects in Alloys, Perkins, J. (Ed.) Plenum Press, N.Y., pp: 517-523.

Huang, X., G.J. Ackland and K.M. Rabe, 2003. Crystal structures and shape-memory behaviour of NiTi. Nature Mater., 2: 307-311. DOI: 10.1038/nmat884

Huiskes, R., H. Weinans, H.J. Grootenboer, M. Dalstra and B. Fudula et al., 1987. Adaptive bone-remodeling theory applied to prosthetic-design analysis. J. Biomech., 20: 1135-1150. PMID: 3429459

Knowles, K.M., D.A. Smith, 1981. The crystallography of the martensitic transformation in equiatomic nickel-titanium. Acta Metall., 29: 101-110. DOI: 10.1016/0001-6160(81)90091-2

Kumar, A., A. Rathi, J., Singh and N.K. Sharma, 2016. Studies on titanium hip joint implants using finite element simulation. Proceedings of the World Congress on Engineering, (WCE' 16). 
Kummer, B., 1986. Biomechanical principles of the statistics of the hip joint. A critical appraisal of a new theory. Zeitschrift Orthopadie und Ihre Grenzgebiete, 124: 179-187.

Kus, K. and T. Breczko, 2010. DSC-investigations of the effect of annealing temperature on the phase transformation behaviour in Ni-Ti Shape Memory Alloy. Mater. Phys. Mechan., 9: 75-83.

Lahoz, R. and J.A. Puértolas, 2004. Training and twoway shape memory in NiTi alloys: Influence on thermal parameters. J. Alloys Compounds, 381: 130-136. DOI: 10.1016/j.jallcom.2004.03.080

Matsumoto, O., S. Miyazaki, K. Otsuka and H. Tamura, 1987. Crystallography of martensitic transformation in Ti-Ni single crystals. Acta Metall., 35: 2137-2144.

DOI: 10.1016/0001-6160(87)90042-3

Mazaheri, M., K. Hassani, A. Karimi and F. Izadi, 2016. Finite element study of composite materials as an alternative for metal hip prothesis using variable load. Mater. Focus, 5: 430-435.

DOI: $10.1166 /$ mat.2016.1342

Meisel, N.A., A.M. Elliott and C.B. Williams, 2014. A procedure for creating actuated joints via embedding shape memory alloys in PolyJet 3D printing. J. Intell. Mater. Syst. Structures. DOI: $10.1177 / 1045389 X 14544144$

Melton, K.N. and O. Mercier, 1980. The mechanical properties of NiTi-based shape memory alloys. Acta Metallurgica, 29: 393-398. DOI: 10.1016/0001-6160(81)90165-6

Mirsayar, M.M., V.A. Joneidi, R.V. Petrescu, F.I.T. Petrescu and F. Berto, 2017. Extended MTSN criterion for fracture analysis of soda lime glass. Eng. Fracture Mechan., 178: 50-59.

DOI: 10.1016/j.engfracmech.2017.04.018

Mirsayar, M.M. and P. Park, 2016. Modified maximum tangential stress criterion for fracture behavior of zirconia/veneer interfaces. J. Mech. Behav. Biomed. Mater., 59: 236-240.

DOI: $10.1016 /$ j.jmbbm.2015.11.037

Miyazaki, S., S. Kimura, K. Otsuka and Y. Suzuki, 1984. The habit plane and transformation strains associated with the martensitic transformation in TiNi single crystals. Scripta Metall., 18: 883-888. DOI: 10.1016/0036-9748(84)90254-0

Mullender, M.G. and R. Huiskes 1995. A proposal for the regulatory mechanism of Wolff's law. J. Orthop Res., 13: 503-512.

DOI: $10.1002 /$ jor. 1100130405

Naresh, C., P.S.C. Bose and C.S.P. Rao, 2016. Shape memory alloys: A state of art review. Mater. Sci. Eng., 149: 012054-012054.

DOI: $10.1088 / 1757-899 X / 149 / 1 / 012054$
New Atlas of Human Anatomy, 2000. New Atlas of Human Anatomy, Editor-in-Chief: Thomas McCracken; Contributor Editor: Richard Walker; Translator: Simona Sânza, Aquila Publishing House, Oradea.

Nikolaev, V.I., S.A. Pul'nev, G.A. Malygin, V.V. Shpeizman and S.P. Nikanorov, 2008. Generation and relaxation of reactive stresses in a $\mathrm{Cu}-\mathrm{Al}-\mathrm{Ni}$ shape memory alloy upon cyclic temperature variation in the range 293-800 K. Phys. Solid State, 50: 2170-2174. DOI: 10.1134/S1063783408110279

Oh, I. and W.H. Harris, 1976. Proximal distribution in the loaded femur. J. Bone Joint Surgery.

Otsuka, K., T. Sawamura and K. Shimuzu, 1971. Crystal structure and internal defects of equiatomic $\mathrm{TiNi}$ martensite. Phys. Stat. Sol., 5a: 457-470. DOI: $10.1002 /$ pssa.2210050220

Otsuka, K. and X. Ren, 1999. Recent developments in the research of shape memory alloys. Intermetallics, 7: 511-528. DOI: 10.1016/S0966-9795(98)00070-3

Otsuka, K., C.M. Wayman, K. Nakay, H. Sakamoto and K. Shimizu, 1976. Superelasticity effects and stressinduced martensitic transformations in $\mathrm{CuAlNi}$ alloys. Acta Metallurgica, 24: 207-226. DOI: 10.1016/0001-6160(76)90071-7

Perillo, L., R. Sorrentino, D. Apicella, A. Quaranta and E. Gherlone et al., 2010. Nonlinear visco-elastic finite element analysis of porcelain veneers: A submodelling approach to strain and stress distributions in adhesive and resin cement. J. Adhesive Dentistry, 12: 403-413. DOI: $10.3290 /$ j.jad.a18394

Petrescu, F.I.T., E. Buzea, L. Nănuţ, M. Neacşa and C. Nan, 2015. The role of antioxidants in slowing aging of skin in a human, Analele Univers. Craiova Biologie Horticultura Tehn. Prel. Prod. Agr. Ing. Med., 20: 567-574.

Petrescu, R.V., R. Aversa, A. Apicella, S. Li and G. Chen et al., 2016a. Something about electron dimension. Am. J. Applied Sci., 13: 1272-1276. DOI: 10.3844/ajassp.2016.1272.1276

Petrescu, R.V., R. Aversa, A. Apicella, F. Berto and S. Li et al., 2016b. Ecosphere protection through green energy. Am. J. Applied Sci., 13: 1027-1032. DOI: 10.3844/ajassp.2016.1027.1032

Petrescu, F.I.T., A. Apicella, R.V. Petrescu, S.P. Kozaitis and R.B. Bucinell et al., 2016c. Environmental protection through nuclear energy. Am. J. Applied Sci., 13: 941-946. DOI: $10.3844 /$ ajassp.2016.941.946

Petrescu, F.I.T. and J.K. Calautit, 2016a. About nano fusion and dynamic fusion. Am. J. Applied Sci., 13: 261-266. DOI: 10.3844/ajassp.2016.261.266 
Petrescu, F.I.T. and J.K. Calautit, 2016b. About the light dimensions. Am. J. Applied Sci., 13: 321-325. DOI: 10.3844 /ajassp.2016.321.325

Pittaccio, S., L. Garavaglia, C. Ceriotti and F. Passaretti, 2015. Applications of shape memory alloys for neurology and neuromuscular rehabilitation. J. Funct. Biomater., 6: 328-344. DOI: $10.3390 /$ jb6020328

Priadko, A.I., V.I. Nikolaev, S.A. Pulnev, S.I. Stepanov and A.V. Rogov et al., 2017. Shape memory Cu-Al$\mathrm{Ni}$ single crystals for application in rotary actuators. Mater. Phys. Mechan., 32:83-87.

Reilly, D.T. and A.H. Burnestain, 1975. The elastic and ultimate properties of compact bone tissue. J. Biomechan., 8: 393-405. DOI: 10.1016/0021-9290(75)90075-5

Reilly, D.T. and A.H. Burstein, 1974. The mechanical properties of cortical bone. J. Bone Joint Surgery, 56: $1001-1021$.

DOI: $10.2106 / 00004623-197456050-00012$

Roger, J., 2015. Leonardo Da Vinci: Anatomist. Brit. J. General Pract., 62: 319.

Rohlmann, A., U. Mossner, G. Bergmann and R. Kolbel, 1982. Finite element analysis and experimental investigations of stresses in a femur. J. Biomed. Eng., 4: 241-246. DOI: $10.1016 / 0141-5425(82) 90009-7$

Shaw, J.A., C.B. Churchill and M.A. Iadicola, 2008. Tips and tricks for characterizing shape memory alloy wire: Part 1-Differential Scanning Calorimetry and basic phenomena. Society Exp. Mechan. DOI: 10.1111/j.1747-1567.2008.00410.x

Šittner, P., L. Heller, J. Pilch, C. Curfs and A. Thiery et al., 2014. Young's modulus of austenite and martensite phases in superelastic NiTi Wires. J. Mater. Eng. Performance, 23: 2303-2314. DOI: $10.1007 / \mathrm{s} 11665-014-0976-\mathrm{x}$

Sofla, A.Y.N., D.M. Elzey and H.N.G. Wadley, 2008. Two-way antagonistic shape actuation based on the one-way shape memory effect. J. Intell. Mater. Syst. Structures, 19: 1017-1027.

Sorrentino, R., D. Apicella, C. Riccio, E. Gherlone and F. Zarone et al., 2009. Nonlinear visco-elastic finite element analysis of different porcelain veneers configuration. J. Biomed. Mater. Res., 91: 727-736. DOI: $10.1002 / \mathrm{jbm}$. b.31449
Sorrentino, R., R. Aversa, V. Ferro, T. Auriemma and F. Zarone et al., 2007. Three-dimensional finite element analysis of strain and stress distributions in endodontically treated maxillary central incisors restored with different post, core and crown materials. Dent Mater., 23: 983-993:

DOI: 10.1016/j.dental.2006.08.006

Tamburrino, F., 2016. Advanced manufacturing for novel materials in industrial design applications, development of a smart and adaptive shadow system using SMAs. Ph.D. Thesis, Italy.

Taylor, D., J.G. Hazenberg and T.C. Lee, 2007. Living with cracks: Damage and repair in human bone. Nat. Mater., 6: 263-268.

DOI: $10.1038 /$ nmat 1866

Van Humbeeck, J., 2010. Introduction to shape memory alloys. Proceedings of the School and Symposium on Smart Structural Systems Technologies, (SST' 10), Porto, Portugal, pp: 3-23.

Velázquez, R. and E.E. Pissaloux, 2012. Modelling and temperature control of Shape Memory Alloys with fast electrical heating. Int. J. Mechan. Control, 13: 1-8.

Viscuso, S. and S. Pittaccio, 2012. Design and implementation of a portable a magnetic shape memory rotary actuator. J. Intell. Mater. Syst. Struct., 24: 454-472. DOI: $10.1177 / 1045389 X 12462648$

Weinans, H., R. Huiskes and H.J. Grootenboer, 1992. The behavior of adaptive bone remodeling simulation models. J. Biomech., 25:1425-1441. PMID: 1491020

Yang, J.H. and C.M. Wayman, 1992. Self-accomodation and shape memory mechanism of $\varepsilon$-martensite-I. Exp. Observ. Mater. Charact., 28: 23-35. DOI: 10.1016/1044-5803(92)90026-E

Yang, H.Z., X.G. Duan and H. Deng, 2013. A study on the force distribution for artificial antagonistic muscles. Mechan. Mater., 278-280: 105-110. DOI: 10.4028/www.scientific.net/AMM.278-280.105

Ziólkowski, A., 2012. On analysis of DSC curves for characterization of intrinsic properties of NiTi shape memory alloys. Proceedings of the 12th International Symposium on Physics of Materials, Sept. 4-8, Prague. 